\title{
Modeling the Effects of Energy Efficient Glazing on Cabin Thermal Energy \& Vehicle Efficiency
}

\author{
A. S. Gravelle* Dr S. Robinson* A. Picarelli $\uparrow$ \\ *Jaguar Land Rover Plc, JLR Research, Vehicle Efficiency, United Kingdom \\ $\uparrow$ Claytex Services Limited, Edmund House, United Kingdom
}

\begin{abstract}
Automotive manufacturers are continually seeking to improve overall vehicle efficiency, one particular area of high energy consumption is the vehicle's HVAC system which can have a significant impact on fuel economy or range in electrically powered vehicles.

Presented in this paper is the work undertaken to understand the ability to model an automotive cabin for a luxury SUV in the Modelica environment including how energy efficient glazing can be modelled to determine improvements in heating or cooling efficiency at extreme ambient temperatures which will have an effect on fuel economy. The effect of air conditioning systems on fuel economy are typically not measured on cycle therefore the real world effect on energy consumption should be quantified.
\end{abstract}

The whole vehicle model and its subsystems including the cabin and HVAC models are built using the Dymola (DYnamic MOdelling LAboratory) multidomain physical systems engineering tool, the modelling approach to each subsystem will be discussed in this paper. The air conditioning system model has been created using $1 \mathrm{~d}$ thermo-fluid physical models. The cabin has been modelled as a multi-zone 1d thermo-fluid model with layering effects.

\section{Introduction}

\subsection{Project Background}

Typically in global climates where high ambient temperatures and high solar irradiance exist temperatures inside the automotive cabin can reach as high as $60^{\circ} \mathrm{C}$ after soaking the vehicle. Therefore the energy consumption required to bring the cabin temperature down to a comfortable level (between $20-25^{\circ} \mathrm{C}$ ) can be significant. In order to do this the load on the air conditioning compressor is high enough to have a big impact on fuel economy.

The pulldown test is typically used to correctly size the HVAC components by applying the highest load to the AC system. Incorrect sizing of the HVAC system has a negative effect on thermal comfort and energy consumed when installed in the vehicle. If a vehicle has been soaked in a hot climate between $12 \mathrm{pm}-3 \mathrm{pm}$ this has a significant impact on pulldown energy requirements and time to comfort in the cabin. The final soak temperature is primarily dominated by: 
surface area of the glazing, cabin volume, solar properties of the glazing, thermal conductivity \& specify heat capacity of materials and the amount of solar radiation from the sun. The pulldown test consists of three 30 minute sections at: $50 \mathrm{kph}$, $100 \mathrm{kph}$ and zero vehicle speed with idle engine speed.

In the case of low emissivity (lowE) or Infra-red reflective (IRR) glazing these have a positive effect on reflecting long wave radiation and the final soak temperature will be lower and therefore pulldown energy requirement and time to comfort will be reduced. As a result the AC system may be downsized due to the cabin now requiring significantly less energy to get to the optimum temperature.

For the models developed a baseline vehicle was developed with standard production glazing and validated against physical climatic wind tunnel test data, therefore results generated with energy efficient glazing were from the model only.

The pulldown test was run with $1000 \mathrm{~W} / \mathrm{m}^{2}$ irradiance from solar lamps directly above the test vehicle, whereas in the warmup test no solar irradiance was applied to the vehicle. $43^{\circ} \mathrm{C}$ and $-18^{\circ} \mathrm{C}$ temperatures were selected to be representative of the extremes of temperatures experienced across the globe. The AC compressor on the test vehicle was fitted with a specially made torque transducer so that changes in compressor torque related to cabin thermal energy could be related back to fuel consumption in the test results.

\section{Efficient glazing effect on energy consumption}

\subsection{Baseline and energy efficient glazing parameters}

For assessing the effect of glazing and insulation on occupant comfort and energy consumption in the modelling environment, relevant input parameters were required for the glazing model in Dymola including: transmission, absorption and emissivity characteristics. Glazing parameters are calculated directly from the supplier spectral data and conductive properties.

\section{Table 1: Glazing input parameters for Dymola model}

\begin{tabular}{|l|c|c|c|}
\hline Baseline Car & lwef & swaf & swtf \\
\hline Front Windshield & H & M & M \\
\hline Panoramic Roof & H & H & L \\
\hline Front Side Window & H & M & M \\
\hline Rear Side Window & H & M & M \\
\hline Rear Windshield & H & M & M \\
\hline Prototype Car & lwef & swaf & swtf \\
\hline Front Windshield (IRR) & M & L & L \\
\hline Panoramic Roof (LowE) & L & H & VL \\
\hline Front Side Window (LowE) & L & M & M \\
\hline
\end{tabular}

Scale:

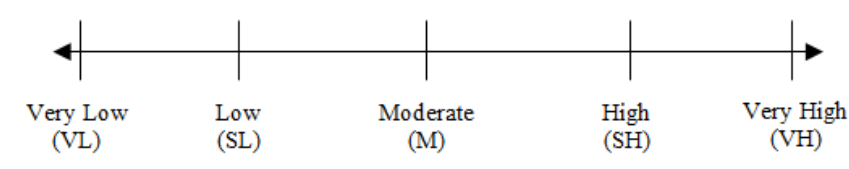

lwef = Long wave emission factor

$k=$ Thermal conductivity [W/m.K]

swaf = Short wave absorption factor

swtf = Short wave transmission factor

As can be seen from the data in Table 1.0 lowE coated glazing has a much lower emissivity value compared to standard glazing which limits the infra-red heating into the cabin. The IRR windshield has a higher emissivity than with LowE coatings but the reflective capability of long wave radiation is much better in IRR glazing, 
IRR glass also has a much lower transmittance of heat into the cabin.

In both vehicle configurations the same glazing was used for the rear side windows and rear windshield as well as considering the effect that glazing targets lower solar energy transmission. Glazing that has a reduced $U$ value was also considered, $U$ value being the amount of heat loss per $\mathrm{m}^{2}$ of material:

$$
R_{t h}=\frac{t}{\lambda} \quad U=\frac{1}{R_{t h}}
$$

Rth $=$ Thermal resistance $\left(m^{2} / K\right) / W$

$t=$ Thickness of the glazing $(m)$

$\lambda=$ Thermal conductivity $(W / m . K)$

$U=U$ value $\left(W / m^{2} . K\right)$

$\mathrm{U}$ value is directly linked to thermal conductivity therefore reducing it should minimise the impact of solar gain during hot climates and prevent loss of heat from the cabin in cold climates. For simulations where low U value glazing is considered, a fixed value of $1.4 \mathrm{~W} / \mathrm{m}^{2} . \mathrm{K}$ has been used.

\subsection{Effects of glazing properties on the cabin environment}

In testing both vehicle configurations (baseline \& advanced glazing) an overall constant solar load of $1000 \mathrm{~W} / \mathrm{m}^{2}$ was used to mimic the typical values for maximum direct solar radiation (excluding the scattering effect). In reality the solar load is not constant but varies with factors such as: time of day, latitude, altitude, time of year, azimuth angle and vehicle tilt angle. The largest contributor to heat flux into the cabin is in the infrared section of the spectral curve. Therefore glazing that targets filtering of the infrared portion of the spectrum are most beneficial to lowering cabin soak temperatures. Figure 1.0 displays the comparison in solar transmittance of the baseline and LowE glazing for the front side windows used in the test vehicle.

The data shows that the transmittance of the infra-red portion of the spectrum above $800 \mathrm{~nm}$ is significantly lower in the LowE glazing compared with the baseline glazing.

The infra-red portion of the spectrum contributes to a significant proportion of cabin heating. The coating side reflectance is significantly higher in the LowE glazing meaning less solar load is emitted into the cabin. Spectral data for the IRR windshield used in the prototype vehicle shows the percentage of transmitted light at the infra-red section of the spectrum is very low (0.6-0.01\%).

Figure 1: Expected solar transmittance for LowE side windows \& baseline (standard) side windows

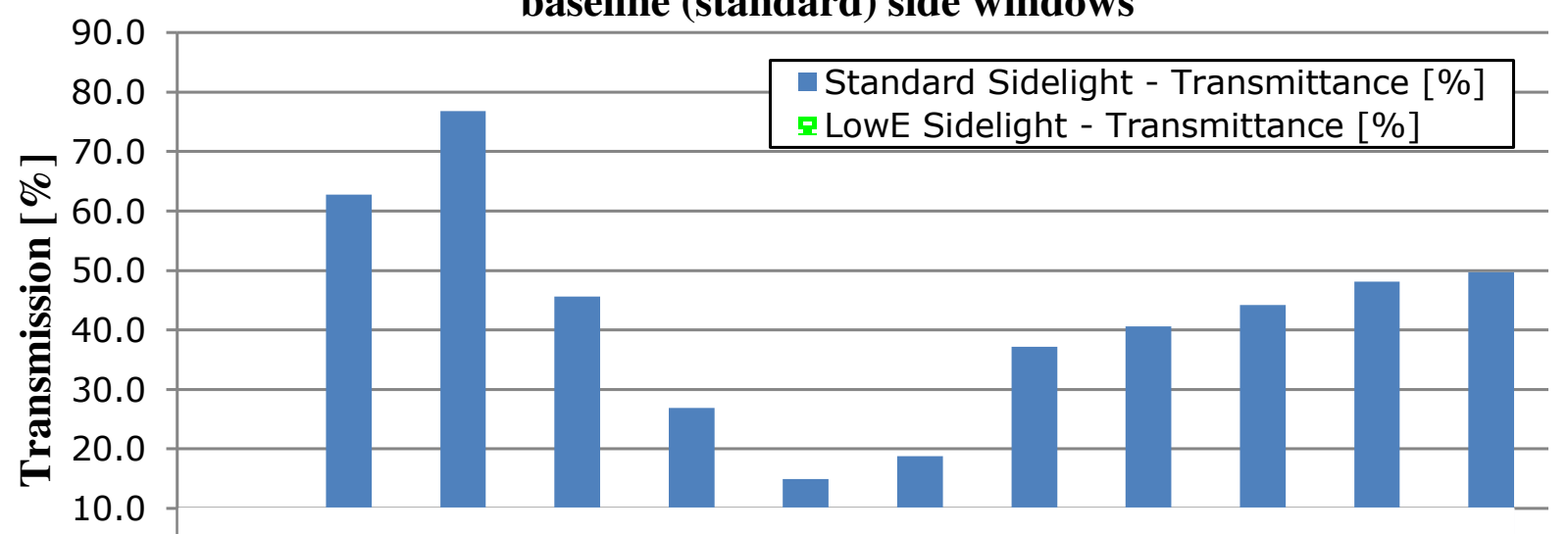

0.0

Figure 2: Experiment level of integrated AC \& cabin model 
The main outcome of the simulations is to compare the effectiveness of LowE and IRR glazing to test data. Typically LowE glazing is able to absorb more thermal energy and emit less radiation however IRR glass may have lower absorption capability but are able to reflect a significantly higher proportion of thermal energy which needs to be compared.

\section{The HVAC \& cabin simulation model}

\subsection{Multi-zone cabin model}

The first step was to develop a physical model of the cabin and the AC system for the test vehicle being used and parameterise each model with data that is representative to the test vehicle. The cabin model was developed around an 8 zone (4 upper and 4 lower occupant zones) cabin from the Dymola Human Comfort library with some modifications to accommodate some of the parameters required for the vehicle.
Figure 2.0 shows the experiment level (top layer) of the model which includes the test data inputs which is fed into the cabin zones, a weather model transmitting ambient conditions to the outside panels of the car and initialization conditions.

There were two versions of this model developed, one that allowed the vent flows from test data to be directly used in the cabin for validation of the cabin model and the 2nd included integrating the HVAC system model to the cabin so that the vent flows are generated by the model and power consumption of the AC compressor can be determined. The AC system was used so that optimisations could be run looking at the effect of different parameters on the cabin temperature in different zones.

The inputs block which feeds the test data into the cabin model includes data such as: engine temperature, trunk temperature, solar load, zonal temperatures and ambient temperature. The experiment also shows two orifices connected to a fluid boundary seen at the bottom right of the screenshot which represent the cabin air exhausts at the back of the car.
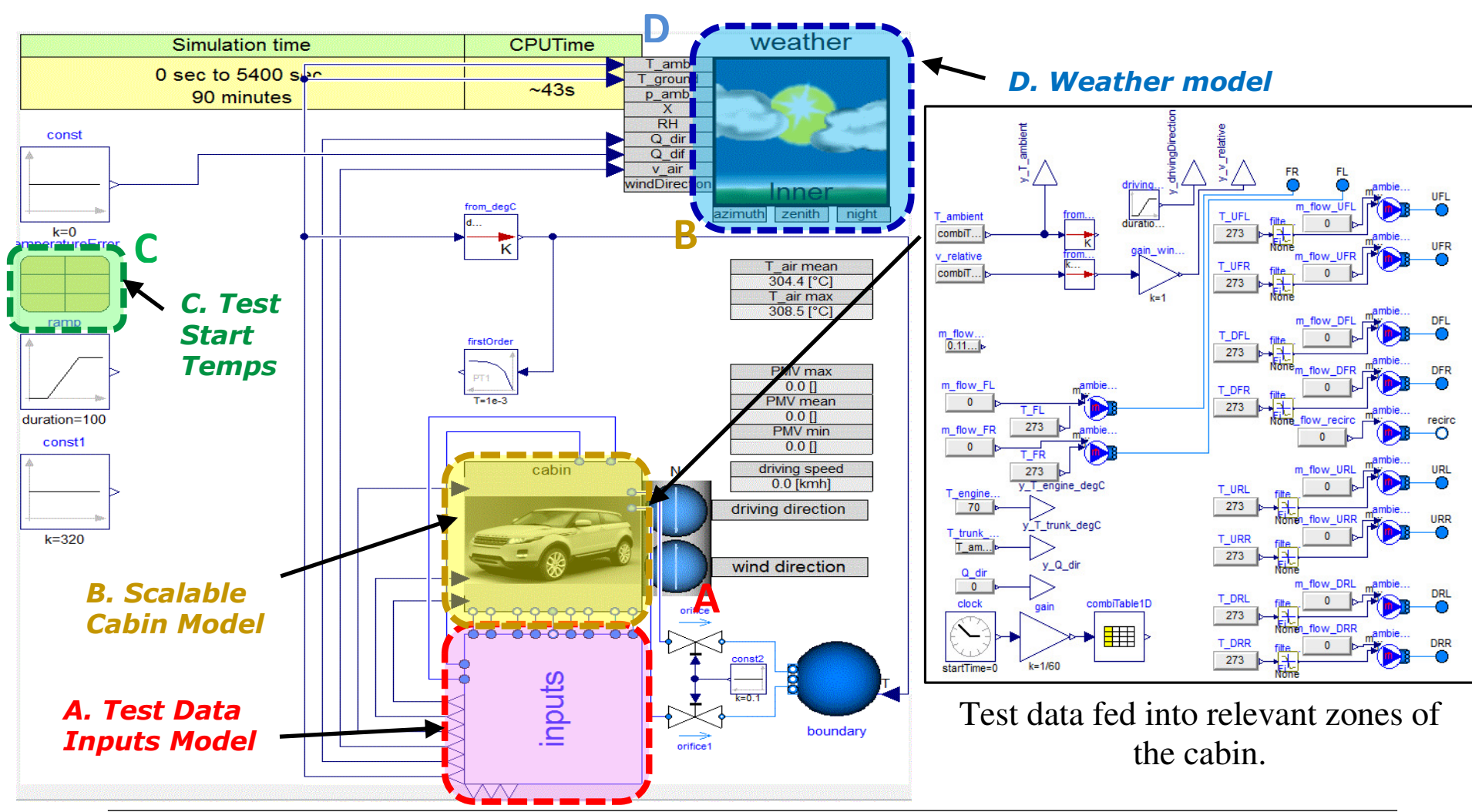

Test data fed into relevant zones of the cabin. 
The weather model feeds in the external ambient conditions to the outside surfaces of the glass and door panels such as: temperature, humidity air velocity \& solar conditions.

A simplistic diagram of the cabin model itself is displayed in Figure 3.0 where in the centre of the model is the air exchange between zones. Vent air flows are fed in typically from the front occupant volumes and air exchange is permitted between upper and lower zones and travels in 1D across the volumes. Each zone has a port volume and a heat port, the volume represents the zonal cabin volume in that region and the heat port is connected to a heat sink which connects directly to the glazing \& trim partitions.

The cabin volumes can be simplistic (1 upper and lower zone only) or very detailed (12 zone cabin with $1 \mathrm{x}$ upper, middle \& lower zone per occupant space).
The cabin model allows for calculation of thermal comfort where for each 'zone column' there is a comfort analysis in that region i.e. for head, chest or legs using parameters such as skin temperature, metabolic rate and clothing. For each of the partitions in the cabin model data records are used to capture the glazing and trim material thermal properties and also the spectral properties if relevant/available. The values detailed in Table 1.0 are applied here and also the azimuth and tilt angles of the partition as well as the positioning and thickness of each relative material within the partition stack.

Due to the complexity of modelling the characteristics of the behaviour of glazing with LowE coating or an IRR layer, for the lowE and IRR glazing the entire glass was modelled with one set of properties as a single layer for both inside and outside surfaces. The trim partitions such as doors, ceiling and floor used multiple layers depending on the structure.

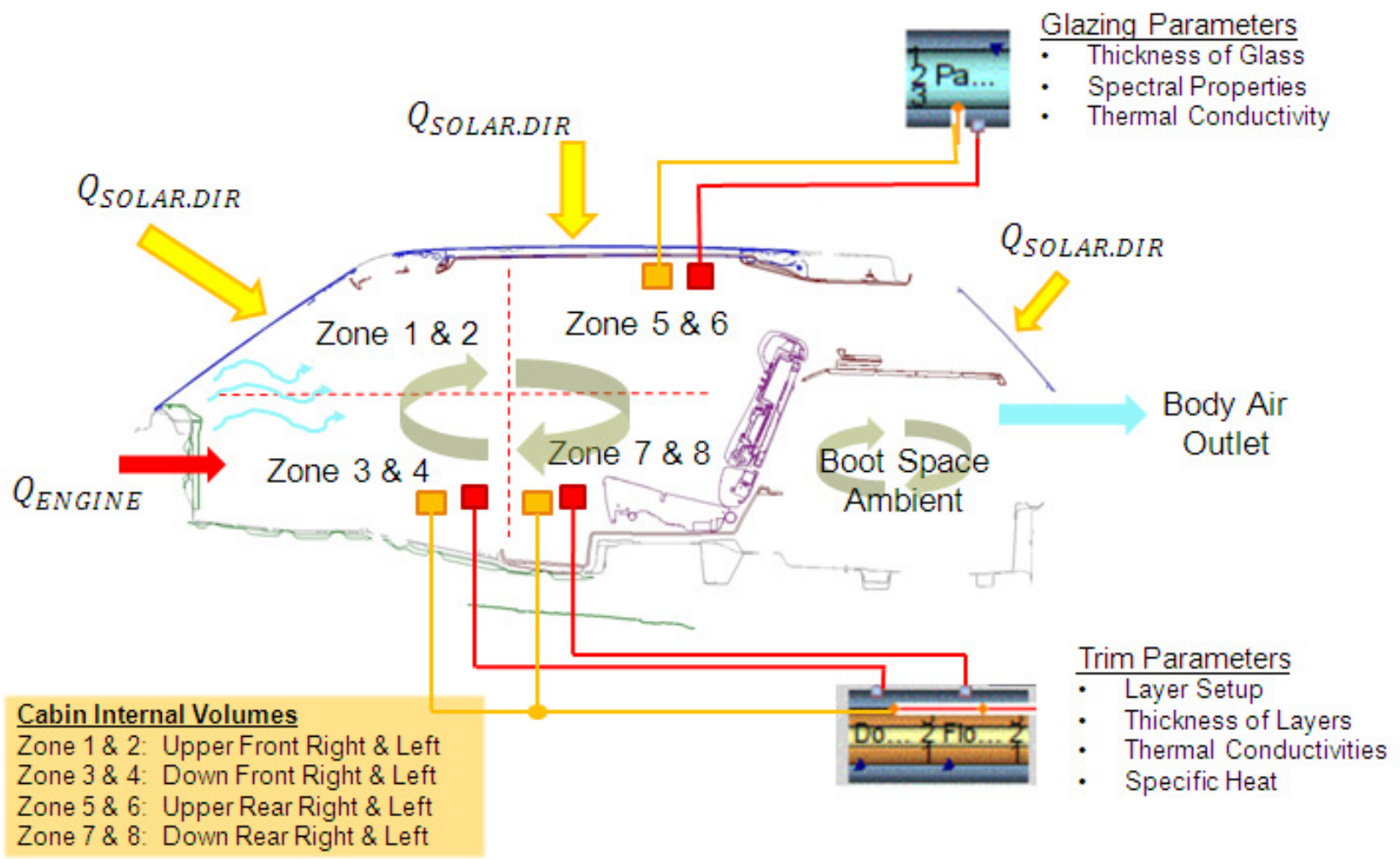

Figure 3: Schematic of cabin model with connected partition models 
The thermal energy gain into the cabin is a combination of the direct solar transmittance [1], radiant heat release [2] and convective heat transfer [3], categorized by the below equations:

$$
\begin{aligned}
& Q=\left(G_{d i r}+G_{d i f}\right) * s w t f \\
& Q=\varepsilon \sigma A\left(T_{2}{ }^{4}-T_{1}{ }^{4}\right) \\
& Q=h A\left(T_{2}-T_{1}\right)
\end{aligned}
$$

\subsection{Air conditioning system model}

The AC system model was built up using templates from the Dymola Air Conditioning library and was fed with the ambient temperature, condenser airflow and initialization values for the AC compressor. The condenser, evaporator and thermal expansion valve 'TXV' are modelled physically with geometrical data for the components and the boundary conditions for the condenser and evaporator are the refrigerant states in and out of the component and the ambient conditions either side of the heat exchanger.
For iterations using the AC loop the cabin zonal temperatures are derived from the evaporator air off temperature modelled within the AC loop and valves are used to represent the relevant air duct paths into the cabin.

The mean cabin temperature was the average of all 8 zonal temperatures which applies to both test data and simulations. The relative humidity of the ambient air also has a large effect on the load of the AC system which is considered in the models. The AC compressor is of variable displacement and uses tabular efficiencies to calculate the mass flow and power consumption of the compressor:

- Volumetric - Volumetric efficiency of the compressor.

- Isentropic - Relating to enthalpy changes across the compressor.

- Effective-Mechanical Efficiency of the compressor

The TXV was modelled using 4 quadrant valve data and based around a TXV within the Dymola AC library. Data from the supplier was used to parameterise the TXV.

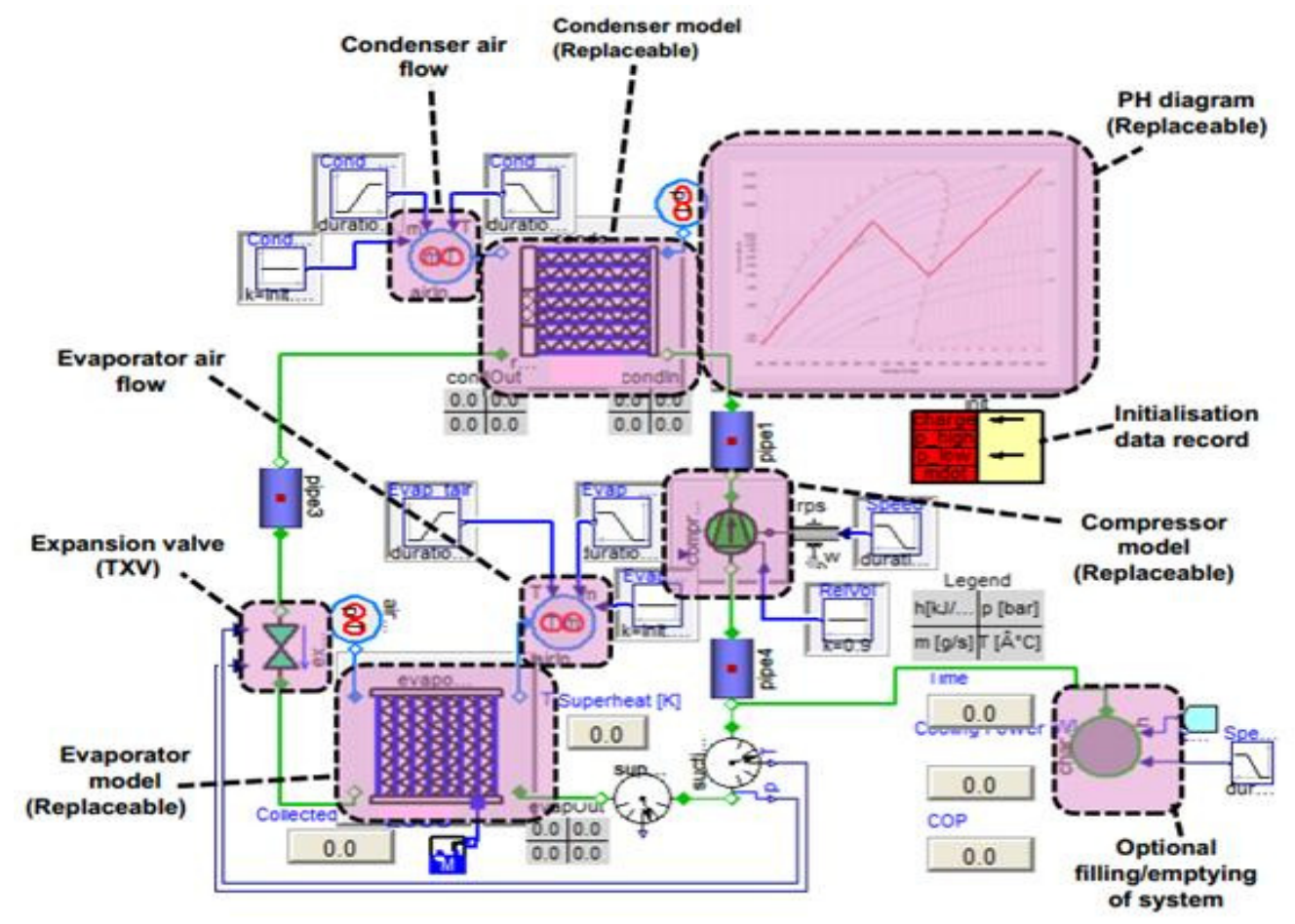


One of the biggest limitations found when modelling the compressor was the ability to parameterize the model at part load conditions due to the difficulty in obtaining data with the required boundary conditions during testing.

The compressor is of variable swash plate angle type such that the displacement can be varied for different load conditions and to prevent icing on the evaporator as opposed to a de-clutching method. Typically the displacement of the compressor reduces when the ratio of pressures between suction and discharge reduce which is controlled by the ambient conditions.

The displacement of the compressor was varied via the use of a PID controller which uses the target evaporator air-off temperature or cabin temperature as the SP value and the model temperature as the PV value to adjust displacement.

\subsection{Vehicle model}

In order to assess the effect of energy consumption from the compressor torque relating to vehicle traction power a vehicle model which integrates the entire AC loop and cabin was generated. Originally a detailed engine warm-up model was included, however these models significantly increased simulation time and were excluded, Fig 5 shows the model that was used for analysis of fuel economy during the climate cycle assessment.

Driver Model: The driver model feeds in the test cycle profile speed, required accelerator pedal position and brake pedal position to the control bus. Any particular drive cycle can be used, i.e. NEDC, Artemis Urban, WLTP.

Engine Model: Is table based and uses MEP and BSFC table data to calculate the fuel flow which is dependent on throttle angle and crank speed and is controlled by the engine controller (ECU)

Transmission Model: Six speed automatic gearbox with torque converter and lockup clutch.
Chassis Model: A simplified model which includes the final drive ratio, friction brakes, wheels, vehicle mass, vehicle resistance (including aero and rolling resistance).

HVAC model: The HVAC model consists of the multi-zone cabin and AC loop where the AC compressor is connected to the accessory flange of the engine. Gearing has been used to represent the AC pulley ratio in relation the engine crankshaft.

Controllers: The engine controller uses a fuelling strategy for idle, overrun and max engine speed and the transmission controller determines the upshift and downshift points based on transmission speed as well as when to engage or disengage the lock-up clutch.

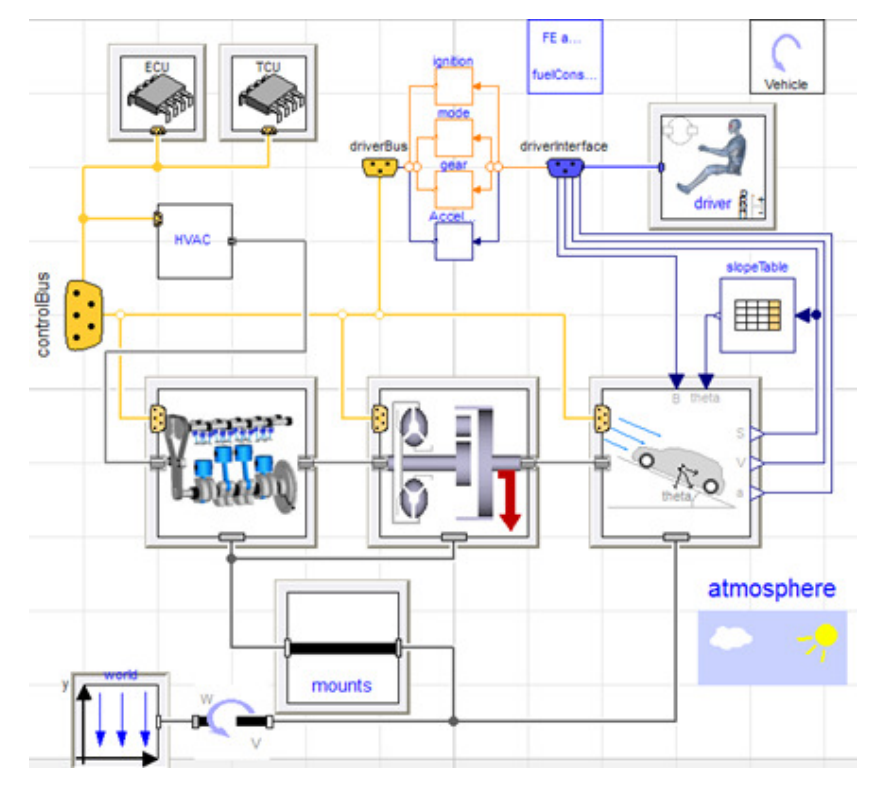

Figure 5: Vehicle Simulation Model

\section{MODEL RESULTS \& ANALYSIS}

\subsection{Correlation of Dymola model to test data}

Once the entire cabin and air conditioning model was developed, a comparison of the baseline model with the test data was conducted. A comparison of the final temperatures between test data and simulation is as follows: 
- Pulldown: $1.5^{\circ} \mathrm{C}$

- Warmup: $2.9^{\circ} \mathrm{C}$

- $43^{\circ} \mathrm{C}$ Soak: $0.5^{\circ} \mathrm{C}$

At the start of the pulldown the cabin temperature drops very quickly due to the AC compressor running at very high displacement to be able to achieve the set point temperature. Towards the end of the pulldown the cabin temperature increases quite considerably, this is because the engine is running at idle speed with the vehicle stationary therefore the rotational speed of the compressor is lower and the airflow over the condenser is significantly reduced and thereby yields reduced cooling power. For the warmup test the heat rejection from the engine is much lower at idle so the coolant temperature passing through the heater core is much lower resulting in a temperature drop.

Figure 7 highlights simulation data for the differences in cabin temperature between different glazing types with a $43^{\circ} \mathrm{C}$ ambient applied, the data in this graph is purely simulation based. The reduction in cabin temperature with energy efficient glass fitted to the vehicle results in a quicker time to comfort than if standard glass were fitted to the car.

The results from the pulldown can be seen in Figure 7 and shows that applying specialised glass coatings has a big effect on lowering cabin temperature.

The most efficient setup in pulldown is to use IRR glazing with a low U value to limit solar gain and conductive heat transfer into the cabin.

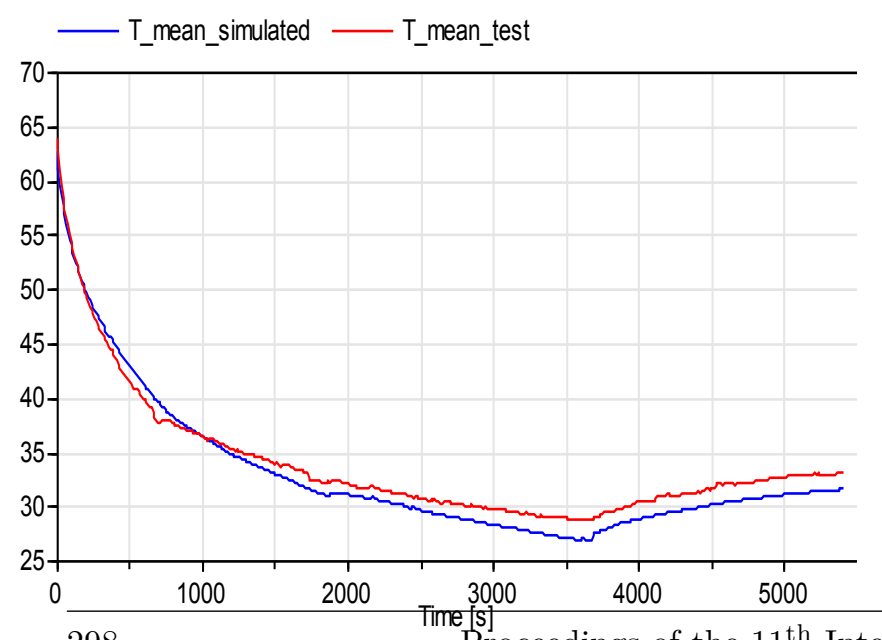




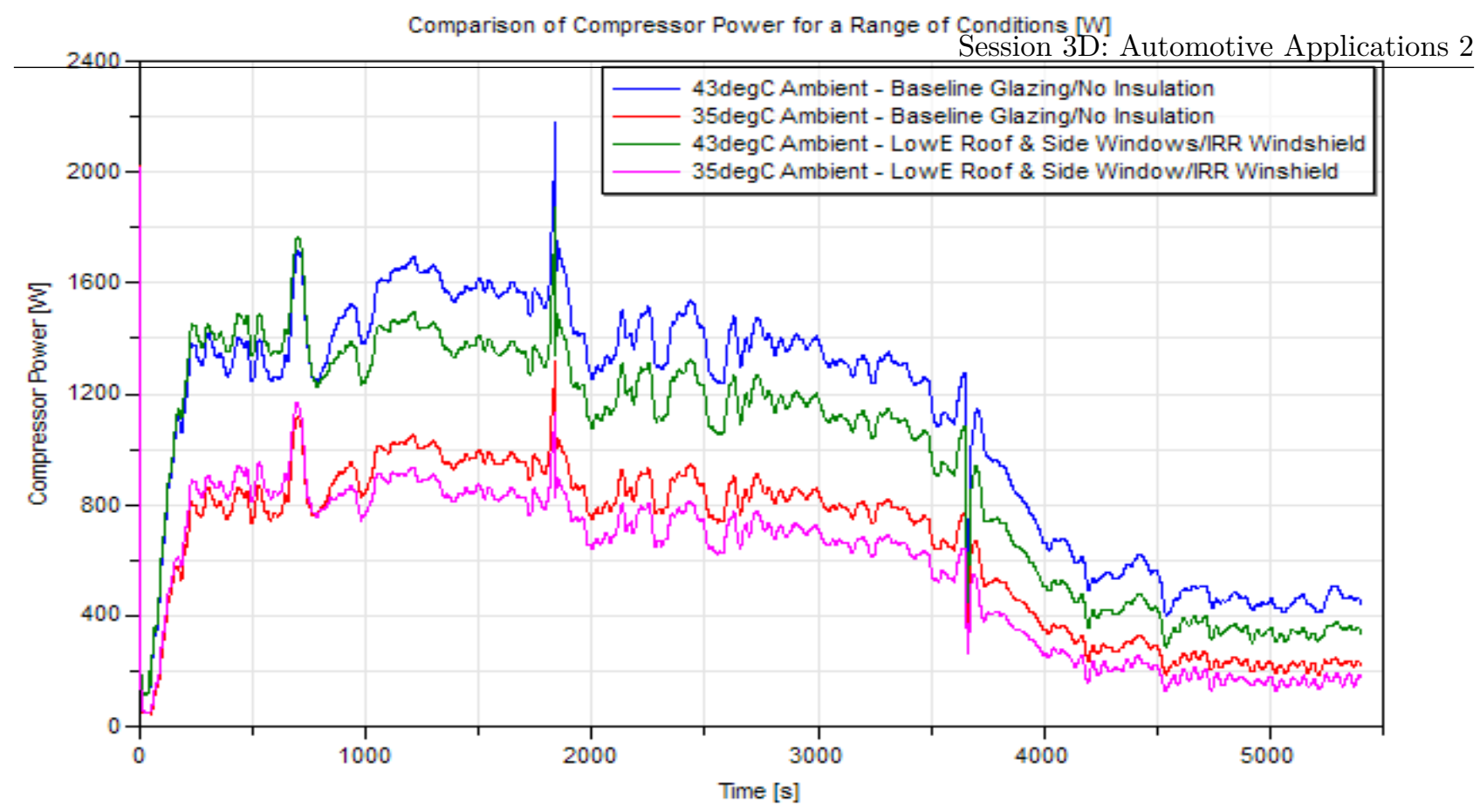

Figure 8: AC compressor torque comparing standard vs. efficient glazing

As can be seen at higher the ambient temperature the glazing has a bigger benefit in terms of fuel economy.

\begin{tabular}{|l|c|}
\hline Condition & FE (\% gain) \\
\hline $50^{\circ} \mathrm{C}$ Ambient benefit & 3.3 \\
\hline $43^{\circ} \mathrm{C}$ Ambient benefit & 2.7 \\
\hline $35^{\circ} \mathrm{C}$ Ambient benefit & 1.4 \\
\hline
\end{tabular}

Table 5: Fuel economy gains for energy efficient glazing

The benefit during the $1^{\text {st }} 30$ minutes is greater at $43^{\circ} \mathrm{C}$ than at $50^{\circ} \mathrm{C}$ due to the compressor running at full displacement for the $50^{\circ} \mathrm{C}$ test for both standard and energy efficient glazing, which means there is no FE benefit during the $1^{\text {st }} 30$ minutes for all configurations.

One observation from the simulations was that the highest contributor of heat flow into the cabin is from the front windshield and the panoramic roof due to their tilt angle relative to the sun, therefore optimising glazing in these areas has the biggest impact on reducing the heat flux into the cabin and reducing the load on the AC compressor.

The glazing has been considered the path of lowest thermal resistance in terms of conduction due to its thickness, therefore applying very low $U$ values to the glazing should have a significant impact.
After generating the base cabin, HVAC and vehicle models it has been concluded that Dymola provides a model with suitable fidelity to estimate the energy benefit of novel cabin technologies. The multi-domain systems integration approach to concept studies that

Dymola provides allows the whole system to be evaluated and optimised. Understanding of the physical interaction between these systems is therefore possible. The systems integrated in this study include cabin and occupant models, AC loop, vehicle powertrain and environment. The following conclusions are established from this work:

1. A high fidelity model of the AC system and cabin model has been developed which allows replaceable components so it can be configured for use in other vehicle platforms.

2. The baseline model correlates well with the baseline test data which was used for validation purposes, therefore the model can be used as a development tool for the vehicle efficiency research team to use and potentially pass onto the mainstream.

3. Simulations show that the glazing in the panoramic roof and front windshield had 
the largest effect on solar gain and fuel economy producing $\mathrm{FE}$ savings as high as $5 \%$ for a $43^{\circ} \mathrm{C}$ pulldown depending on conditions.

4. The reduction in cabin temperature for energy efficient glazing compared to baseline windows for a 3 hour solar soak was in the order of $3-4^{\circ} \mathrm{C}$, also for the pulldown this allowed a $3^{\circ} \mathrm{C}$ reduction in cabin temperature.

5. For the $-18^{0} \mathrm{C}$ warmup test the LowE glazing alone had no impact on increasing the average cabin temperature, reducing the $U$ value of the improved the warmup capability of the cabin. However the mode of heat transfer in this case is mostly convective.

\section{ACKNOWLEDGMENTS}

The authors would like to thank all the people that helped generate the content of this paper: Dr. Jonathan Parsons MInstP for providing glazing spectral properties calculated from supplier data, MIRA test facility center for experimental data and Claytex services for modeling support on the project.

\section{BIBLIOGRAPHY}

[1] Michigan Scientific Corporation, "User Manual for Pulley Torque Measurement System", Milford, MI, USA, September 2013

[2] Green Rhino Energy, "Defining Standard Spectra for Solar Panels", http://www.greenrhinoenergy.com/solar/radiati on/spectra.php

[3] A. S. Gravelle, "A multi-domain thermo fluid approach to optimising HVAC systems", IMA conference proceedings, Engineer's House, Bristol, September 2014

[4] S Shendge, P Tilekar, S Dahiya and S Kappor, "Reduction of MAC Power
Requirement in a Small Car" SAE Paper 201001-0803, April 2010

[5] S Gasworth, T Tankala, "Effect of Glazing Thermal Conductivity on Cabin Soak

Temperature" SAE Paper 2012-01-1207, April 2012

[6] T Han, Kuo-Huey Chen, "Assessment of Various Environmental Thermal Loads on Passenger Compartment Soak and Cool-down Analyses" SAE Paper 2009-01-1148,

[7] D Turler, D Hopkins, H Goudey, "Reducing Vehicle Auxiliary Loads Using Advanced Thermal Insulation and Window Technologies" SAE Paper 2003-01-1076 